\title{
Effects of Three Kinds of Dietary Nitrogen Sources on the Metabolic Fate of Tryptophan
}

\author{
Katsumi SHIBAta and Michiko OnODERA \\ Department of Food Science and Nutrition, Teikoku Women's University, \\ Moriguchi, Osaka 570, Japan \\ Received May 8, 1991
}

\begin{abstract}
We have recently reported that the conversion ratio of tryptophan to nicotinamide [urinary excretion of (nicotinamide $+N^{1}$-methylnicotinamide (MNA) $+N^{1}$-methyl-2-pyridone-5-carboxamide $(2-\mathrm{Py})+N^{1}$-methyl-4-pyridone-3-carboxamide (4-Py) $(\mu \mathrm{mol} /$ day)/tryptophan intake during urine collection $(\mu \mathrm{mol} / \mathrm{day})]$ was changeable according to the kind of dietary nitrogen sources. In these experiments, we investigated whether the fate of tryprophan is changeable according to nitrogen sources or not. Weanling rats were fed with a diet low in nitrogen $(1.1311 \%$ nitrogen) containing a suitable amount of nicotinic acid $(6 \mathrm{mg} / 100 \mathrm{~g}$ of diet) for 17 days. Egg white (EW), egg white proteolysate-5 (EWP-5), and mixture of amino acids simulating the amino acid pattern of EWP-5 were used as dietary nitrogen sources. The urinary excretion of 5-hydroxyindole-3-acetic acid and the sum of nicotinamide and its metabolites in the group fed with the EWP-5 diet was the lowest, but, the excretion ratio of (2-Py +4-Py)/MNA, which has been reported to be an index of amino acid adequacy, in the group fed with the EWP-5 diet was the highest. From these findings, it was suggested that the tryptophan in EWP-5 (mixtures of small peptides) entered the degradation pathway of tryptophan such as serotonin and nicotinamide biosynthesis with difficulty, but that it was easy to enter the protein biosynthesis, compared with tryptophan in $\mathrm{EW}$ (protein and mixtures of amino acids).
\end{abstract}

We have recently reported that the tryptophan to nicotinamide conversion is changeable according to dietary nitrogen sources; namely, the degree of tryptophan to nicotinamide conversion [urinary excretion of (nicotinamide + $N^{1}$-methylnicotinamide (MNA) $+N^{1}$-methyl2-pyridone-5-carboxamide (2-Py) $+N^{1}$-methyl-4-pyridone-3-carboxamide (4-Py) ( $\mu \mathrm{mol} /$ day)/tryptophan intake $(\mu \mathrm{mol} / \mathrm{day})]$ was protein (egg white; EW) $>$ mixtures of amino acids $>$ mixtures of small peptides (egg white proteolysate-5; EWP-5). ${ }^{1)}$ In our opinion, this phenomenon is a consequence of the fact that a part of tryptophan in mixtures of small peptides is more efficiently used for protein synthesis than tryptophan in protein and mixtures of amino acids, however, this proposal is not commonly accepted. In this connection, we have reported that the body weight gain of rats fed with a diet low in protein containing a suitable amount of nicotinic acid increases significantly when the rats are fed with the diet adding the limiting amino acids. ${ }^{2,3)}$ Fur- thermore, we have reported that the urinary excretion of the sum of nicotinamide and its metabolites such as MNA, 2-Py and 4-Py is lower in the groups fed with low protein diets with the limiting amino acids added than in the groups fed with low protein diets. However, the resulting excretion ratio of $(2-\mathrm{Py}+4-$ Py)/MNA is the reverse. ${ }^{2,3)}$ These phenomena are also considered to be the result of tryptophan in EWP-5 being preferentially used in protein synthesis because of improvement of amino acid nutrition, which is commonly accepted, because Vivian et al., ${ }^{4)}$ Brown et al., ${ }^{5}$ and Chaloupka et $a{ }^{6}{ }^{6)}$ reported that tryptophan was used first to establish and maintain nitrogen equilibrium, second for the synthesis of blood NAD, and finally, when blood NAD had reached nearly normal levels, there was an increase in the urinary excretion of MNA and 2-Py. The object of these experiments is to find whether EWP-5 is a superior nitrogen source to EW protein and the mixtures of amino acids, and wherether the conversion 
ratio of tryptophan to nicotinamide and serotonin is changeable accoridng to the kind of dietary nitrogen sources.

\section{Materials and Methods}

Chemicals. 2-Py and 4-Py were syntyesized by the methods of Pullman and Colowick and Shibata et al., ${ }^{8}$ ) respectively. MNA chloride was obtained from Tokyo Kasei Kogyo Co. (Tokyo, Japan). Nicotinamide was obtained from Wako Pure Chemical Industries Co. (Osaka, Japan). 5-Hydroxyindole-3-acetic acid (5-HIAA) was purchased from Aldrich Chemical Co., Inc. (Milwaukee, WI, U.S.A.). All the other chemicals used were of the highest purity available from commercial sources.

Animals and diets. Male rats of the Sprague-Dawley

Table I. Composition of Diets

\begin{tabular}{lccc}
\hline & $\begin{array}{c}9.08 \% \mathrm{AA}^{* 6} \\
\text { (EWP-5 } \\
\text { pattern) }\end{array}$ & $\begin{array}{c}9.59 \% \\
\text { EW }\end{array}$ & $\begin{array}{c}10.0 \% \\
\text { EWP-5 }\end{array}$ \\
& \multicolumn{3}{c}{ g/100 g of diet } \\
& 9.09 & 9.59 & 10.0 \\
& 53.28 & 52.94 & 52.67 \\
N-Source*1 & 26.64 & 26.47 & 26.33 \\
$\begin{array}{l}\alpha \text {-Cornstarch*2 } \\
\text { Sucrose*3 }\end{array}$ & 5.0 & 5.0 & 5.0 \\
$\begin{array}{l}\text { Corn oil } \\
\text { Mineral mixture*5 }\end{array}$ & 5.0 & 5.0 & 5.0 \\
$\begin{array}{l}\text { (Oriental's ratio) } \\
\text { Vitamin mixture*5 } \\
\text { (Oriental's ratio) }\end{array}$ & 1.0 & 1.0 & 1.0 \\
\hline $\begin{array}{l}\text { Nicotinic acid content } \\
\text { (mg/100g of diet) }\end{array}$ & 6.0 & 6.0 & 6.0 \\
$\begin{array}{l}\text { Tryptophan content } \\
\text { (mg/100g of diet) }\end{array}$ & 83.0 & 104.0 & 83.0 \\
\hline
\end{tabular}

*1 The content of nitrogen in each diet was adjusted to $1.1311 \%$. EW and EWP-5 were gifts from Eisai Co. (Tokyo, Japan). Amino acids were puchased from Wako Pure Chemical Industries Ltd. (Osaka, Japan).

*2 Obtained from Nichiden Kagaku Co. (Tokyo, Japan).

*3 Obtained from Wako Pure Chemical Industries Ltd.

*4 Obtained from Ajinomoto Co. (Tokyo, Japan).

*5 Compositions of mineral and vitamin mixture are described in ref. 3. Obtained from Oriental Yeast Kogyo Co. (Tokyo, Japan).

*6 Arg HCl, $0.595 \%$; Lys $\mathrm{HCl}, 0.744 \%$; His $\mathrm{HCl} \mathrm{H}_{2} \mathrm{O}$, $0.301 \%$; Phe, $0.493 \%$; Tyr, $0.312 \%$; Leu, $0.745 \%$; Ile, $0.442 \%$; Met, $0.330 \%$; Val, $0.629 \%$; Ala, $0.539 \%$; Gly, 0.294\%; Pro, 0.313\%; Glu, $1.170 \%$; Ser, $0.625 \%$; Thr, $0.388 \%$; Asp, $0.863 \%$; Trp, $0.083 \%$; Cystine, $0.213 \%$. strain ( 3 weeks old) were purchased from Clea Japan Inc. (Tokyo, Japan). The rats were placed in individual metabolic cages (CT-10; Clea Japan) on arrival and fed with a diet low in amino acids, EWP-5, or EW containing $0.006 \%$ nicotinic acid (Table I) ad libitum for 17 days. Urine samples (09:00 09:00 hr, $24 \mathrm{hr}$ ) were collected on the last day, and the rats were killed by decapitation at 09:00-10:00 hr and the livers, brains, upper part of small intestines $(30 \mathrm{~cm}-\mathrm{long})$, and blood were removed and a portion of each was immediately prepared for the analysis of total nicotinamide. Urine samples were stored at $-25^{\circ} \mathrm{C}$ until analysis. Urine content of 5-HIAA was immediately measured after the urine collection.

The temperature in the animal room was kept at $22 \pm 2{ }^{\circ} \mathrm{C}$, the humidity was about $60 \%$, and a 12 -hr light-dark cycle was maintained.

Analyses. Urine contents of nicotinamide, 2-Py, and 4-Py were simultaneously measured by the high-performance liquid chromatographic (HPLC) method of Shibata et $a l^{8)}$ Urine content of MNA was measured by the HPLC method of Shibata ${ }^{91}$ The preparation for measurement of total nicotinamide content in liver, brain, small intestine, and whole blood was described in ref. 10, and the nicotinamide contents were measured by the HPLC method of Shibata et al. ${ }^{81}$ Urine content of 5-HIAA was measured by the HPLC method of Shibata et al. ${ }^{10}$

\section{Results}

\section{Effects of three kinds of dietary $N$-sources on gain in body weight, food intake, food efficiency ratio}

As, shown in Table II, the gain in body weight and food efficiency ratio were higher in the groups fed with the EWP-5 and EW diets than in the group fed with the amino acid (AA) diet, although no difference in food intakes among the three groups were observed.

The intakes of food, nicotinic acid, and tryptophan during uring collection (the last day of the experiment) are also given in Table II. The nicotinic acid intake was about the same in the three groups, but, the tryptophan intake had a tendency to be higher in the group fed with the EW diet than in the groups fed with the AA and EWP-5 diets.

\footnotetext{
Effects of three kind of dietary $N$-sources on urinary excretion of 5-HIAA, nicotinamide, and its metabolites, and the resulting excretion ratio of $(2-P y+4-P y) / M N A$

The degree of the urinary excretion of
} 
Table II. EfFects of THREe Kind of Dietary Nitrogen Sources on Gain in Body Weight, Food Intake, Food Efficiency Ratio (FER), Nicotinic Acid INTAKE, AND TRYPTOPHAN INTAKE DURING Urine Collection in Rats

Male rats of the Sprague-Dawley strain ( 3 weeks old) were fed with a $9.08 \%$ amino acid (AA) diet simulated tha amino acid pattern of egg white proteolysate- 5 (EWP-5) $9.59 \%$ egg white (EW) diet, or $10.0 \%$ EWP-5 diet for 17 days ad libitum.

\section{AA \\ EWP-5 \\ EW}

Gain in body weight

(g/17 days) $\quad 58.4 \pm 4.0^{a} \quad 85.4 \pm 3.7^{b} \quad 86.0 \pm 4.5^{b}$

Food intake during experiment

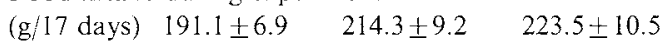
FER $\quad 0.305 \pm 0.007^{\mathrm{a}} \quad 0.399 \pm 0.002^{\mathrm{b}} 0.395 \pm 0.010^{\mathrm{b}}$

Food intake during urine collection (day 16 day 17) (g/day) $\quad 14.3 \pm 0.8 \quad 15.5 \pm 1.7 \quad 15.0 \pm 1.3$ Nicotinic acid intake during urine collection (day 16 -day 17)

$\begin{array}{llll}(\mu \mathrm{mol} / \mathrm{day}) & 6.96 \pm 0.42 & 7.53 \pm 0.84 & 7.33 \pm 0.63\end{array}$

Tryptophan intake during urine collection

(day 16-day 17)

$\begin{array}{llll}(\mu \mathrm{mol} / \mathrm{day}) & 58.0 \pm 3.5 & 62.8 \pm 7.0 & 76.6 \pm 6.6\end{array}$

Values are means \pm SEM for 5 rats; values with different superscript letters in the same row are significantly different at $p<0.05$ as measured by Duncan's new multiple range test. $^{12)}$

Table III. EFFECTS OF Kind OF DieTARY Nitrogen SOURCES ON URINARY EXCRETION OF 5-HIAA, NAM, and Its Metabolites, the Resulting Excretion RATIO OF (2-Py+4-Py)/MNA IN RATS

\begin{tabular}{|c|c|c|c|}
\hline & $\mathrm{AA}$ & EWP-5 & $E W$ \\
\hline $\begin{array}{l}\text { 5-HIAA } \\
\text { (nmol/day) }\end{array}$ & $146.4 \pm 11.7^{a}$ & $88.27 \pm 8.9^{b}$ & $194.6 \pm 10.1^{c}$ \\
\hline $\begin{array}{l}\text { Nam } \\
\text { (nmol/day) }\end{array}$ & $178 \pm 25^{\mathrm{a}}$ & $192 \pm 24^{a}$ & $433 \pm 17^{b}$ \\
\hline $\begin{array}{l}\text { MNA } \\
\text { (nmol/day) }\end{array}$ & $2416 \pm 326^{a}$ & $626 \pm 125^{b}$ & $1782 \pm 368^{a}$ \\
\hline $\begin{array}{l}\text { 2-Py } \\
\text { (nmol/day) }\end{array}$ & $281 \pm 71^{\mathrm{a}}$ & $248 \pm 20^{a}$ & $437 \pm 36^{b}$ \\
\hline $\begin{array}{l}\text { 4-Py } \\
\text { (nmol/day) }\end{array}$ & $1080 \pm 472^{a}$ & $1578 \pm 26 \mathrm{I}^{\mathrm{a}, \mathrm{b}}$ & $2310 \pm 274^{b}$ \\
\hline $\begin{array}{l}\text { Sum*1 } \\
\text { (nmol/day) }\end{array}$ & $4418 \pm 578^{a}$ & $2799 \pm 166^{b}$ & $4963 \pm 265^{a}$ \\
\hline $\begin{array}{l}(2-\mathrm{Py}+4-\mathrm{Py}) \\
\text { MNA }\end{array}$ & $0.73 \pm 0.35^{\mathrm{a}}$ & $3.70 \pm 0.65^{\mathrm{b}}$ & $1.76 \pm 0.22^{\mathrm{a}}$ \\
\hline
\end{tabular}

Values are means $\pm S E M$ for 5 rats; values with different superscript letters in the same row are significantly different at $p<0.05$ as measured by Duncan's new multiple range test. ${ }^{12)}$

$* 1 \quad \mathrm{Nam}+\mathrm{MNA}+2-\mathrm{Py}+4-\mathrm{Py}$.
Table IV. EFFects of Kind of Dietary Nitrogen Sources on Liver Weight, Total Nicotinamide Contents in Liver, Small Intestine, BRAIN, AND WHOLE BLOOD

\begin{tabular}{lccc} 
& AA & EWP-5 & EW \\
\hline Liver weight $(\mathrm{g})$ & $5.71 \pm 0.27$ & $6.10 \pm 0.46$ & $6.34 \pm 0.4$ \\
Liver $(\mathrm{nmol} / \mathrm{g})$ & $1289 \pm 68$ & $1374 \pm 44$ & $1443 \pm 78$ \\
Small intestine & $518 \pm 44$ & $531 \pm 23$ & $516 \pm 28$ \\
$\quad(\mathrm{nmol} / \mathrm{g})$ & & & \\
Brain $(\mathrm{nmol} / \mathrm{g})$ & $513 \pm 15$ & $586 \pm 19$ & $530 \pm 8$ \\
Whole blood & $124 \pm 6$ & $130 \pm 7$ & $138 \pm 4$ \\
$\quad(\mathrm{nmol} / \mathrm{ml})$ & & & \\
\hline
\end{tabular}

Values are means \pm SEM for 5 rats.

5-HIAA was EW diet $>$ AA diet $>$ EWP-5 diet, as shown in Table III. The urinary excretion of nicotinamide and 2-Py was higher in the group fed with the EW diet than in the groups fed with the AA and EWP-5 diets (Table III). The urinary excretion of MNA was lower in the group fed with the EWP-5 diet than in the groups fed with the AA and EW diets. The urinary excretion of 4-Py in the group fed with EW diet was higher than that in the group fed with the AA diet and had a tendency to be higher than that in the group fed with the EWP-5 diet. And the urinary excretion of the sum of nicotinamide, MNA, 2-Py, and 4-Py was lower in the group fed with the EWP-5 diet than in the groups fed with the AA and EW diets, as shown in Table III. However, the excretion ratio of $(2-\mathrm{Py}+$ 4-Py)/MNA was higher in the group fed with the EWP-5 diet than in the groups fed with the AA and EW diets.

\section{Effects of three kind of dietary $N$-sources on liver weight, total nicotinamide contents in liver, small intestine, brain, and whole blood \\ The liver weight in the group fed with the} AA diet was slightly lower than that in the groups fed with the EW and EWP-5 diet. No difference in total nicotinamide contents in the livers of the three $\mathrm{N}$-source diets were observed, as shown in Table IV. A similar result was obtained in the brains, small intestines, and whole blood. 


\section{Discussion}

We have recently reported that the order of conversion ratio of tryptophan to nicotinamide was $\mathrm{EW}>\mathrm{AA}>\mathrm{EWP}-5$, when rats were fed with nicotinic acid-free diets containing suitable amounts of nitrogen source. ${ }^{1)}$ Namely, tryptophan in the small peptides (EWP-5) enters the degradation pathways of tryptophan such as nicotinamide biosynthesis with difficulty compared with that in mixtures of amino acids and protein. This experiment was done to confirm this phenomenon and to investigate whether the metabolic fate of tryptophan differs depending on the kind of nitorgen sources or not.

In these experiment with the low nitrogen source as was reported previously, ${ }^{13)}$ the gain in body weight in the group fed with the EWP5 diet was higher than that in the group fed with the AA (simulated EWP-5 pattern) diet and almost the same in the group fed with the EW diet (Table II), although tryptophan intake was 1.25 -fold higher in the group fed with the EW diet than in the group fed with the EWP-5 diet. In this connection, the first limiting amino acids of EWP-5 and EW are both tryptophan and its amino acid value is 67 and 80 , respectively. ${ }^{13)}$ The same body weight gain in the groups between the EW and EWP-5 diet indicates that tryptophan in the EWP-5 is more efficiently used for protein synthesis than in that in EW and mixtures of amino acids.

The order of urinary excretion of 5-HIAA, a urinary metabolite of serotonin, was EW diet $>$ AA diet $>$ EWP-5 diet (Table III), indicating that tryptophan in the EWP-5 (mixtures of small peptides) entered the degradation pathways of tryptophan such as serotonin biosynthesis with difficulty.

The urinary excretion of MNA in the group fed with the AA diet was four-fold higher than that in the group fed with the EWP-5 diet and had a tendency to be higher than that in the group fed with the EW diet (Table III). The urinary excretion of the sum of nicotinamide, MNA, 2-Py, and 4-Py in the group fed with the EWP-5 diet was the lowest in the three groups (Table III), indicating that tryptophan in EWP-5 enters the degradation pathways of tryptophan such as nicotinamide biosynthesis with difficulty as well as the serotonin pathway. A similar phenomenon was reported by us. ${ }^{2,3}$ Namely, the urinary excretion of the sum of nicotinamide and its metabolites was higher in the group fed with a diet low in protein containing $0.006 \%$ nicotinic acid (basal diet) than in the group fed with the basal diet adding the limiting amino acids, although body weight gain and food intake were lower in the group fed with the basal diet than in the group fed with the added diet. The higher excretion ratio of (2-Py + 4-Py)/MNA is observed when these is a significant decrease in MNA excretion along with a significant increase in 4-Py excretion. This phenomenon is observed when amino acid nutrition was improved by adding the low protein diets with the limiting amino acids. The excretion ratio was the highest in the group fed with the EWP-5 diet in the three groups (Table III). In our opinion, the findings in these experiment indicate that EWP-5 is a superior nitrogen source to EW and mixtures of amino acids.

Total nicotinamide contents in liver, small intestine, brain, and whole blood of the three groups were almost the same (Table IV) and these values are within normal range. Namely, this means that the body nicotinamide pool in the three groups is saturated under these conditions. Therefore, the comparison among the conversion ratio of tryptophan to nicotinamide in the three groups is possible. The urinary excretion of the sum of nicotinamide, MNA, 2-Py, and 4-Py in the group fed with the EWP-5 diet was the lowest (Table III). It is not possible to calculate the tryptophan-nicotinamide conversion because the diets used contain nicotinic acid, however, it is clear that the group fed with the EWP-5 diet had the lowest conversion since the urinary excretion of nicotinamide and its metabolites in the EWP-5 group is lowest in the three groups.

In conclusion, the lowest conversion of tryptophan to nicotinamide and to 5-HIAA 
being in the group fed with the EWP-5 diet means that tryptophan in EWP-5 enters the degradation pathways of tryptophan such as biosynthetic pathways of nicotinamide and serotonin with difficulty. However, the body weight gain of weanling rats was higher in the EWP-5 group than in the AA group and almost the same as in the EW group. The first limiting amino acid of the diets used is tryptophan. Therefore, it is possible that tryptophan in EWP-5 (mixtures of small peptides) has higher bioavailability for protein synthesis than that in EW (protein) and mixtures of amino acids.

\section{References}

1) K. Shibata and M. Onodera, Agric. Biol. Chem., 55, $1291(1991)$.
2) K. Shibata, Agric. Biol. Chem., 53, 1427 (1989).

3) K. Shibata and H. Matsuo, J. Nutr., 119, 896 (1989).

4) V.M. Vivian, M. M. Chaloupka and M. S. Reynolds, J. Nutr., 66, 587 (1958).

5) R. R. Brown, V. M. Vivian, M. S. Reynolds and J. M. Price, J. Nutr., 66, 599 (1958).

6) M. M. Chaloupka, J. N. Williams, Jr., M. S. Reynolds and C. A. Elvehjem, J. Nutr., 63, 361 (1957).

7) M. E. Pullman and S. P. Colowick, J. Biol. Chem., 206, 1489 (1954).

8) K. Shibata, T. Kawada and K. Iwai, J. Chromatogr., 424, 23 (1988).

9) K. Shibata, Vitamins (Japan), 61, 599 (1987).

10) K. Shibata, Vitamins (Japan), 62, 225 (1988).

11) K. Shibata, M. Onodera, T. Kawada and K. Iwai, J. Chromatogr., 430, 381 (1988).

12) K. Wakabayashi, "Zikken Data no Seiri," Baifukan Co., Japan, 1984, p. 44.

13) K. Shibata, T. Suzuki and K. Iwai, J. Nutr. Food Sci., 40, 279 (1987). 